\title{
Mayer-Rokitansky-Kuster-Hauser Syndrome (MRKH) Patients Treated with Laparoscopic Neovaginal with The Davydov Procedure with Epidural Anesthesia: A Case Report
}

\author{
Hadrians Kesuma Putra ${ }^{1 *}$, Amir Fauzi ${ }^{1}$, Ratih Krisna ${ }^{1}$, Aerul Chakra Alibasya ${ }^{2}$, Aidyl Fitrisyah ${ }^{3}$, Alia
}

Desmalia $^{4}$

${ }^{1}$ Department of Obstetrics and Gynecology, Uroginecology Division, Faculty of Medicine Sriwijaya University/ Mohammad Hoesin Hospital, Palembang, Indonesia

${ }^{2}$ Department of Obstetrics and Gynecology, Fertilization and Endocrine Division, Faculty of Medicine Sriwijaya University/ Mohammad Hoesin Hospital Palembang, Palembang, Indonesia

${ }^{3}$ Department of Anesthesiology, Faculty of Medicine Sriwijaya University/ Mohammad Hoesin Hospital, Palembang, Indonesia

${ }^{4}$ Resident of Obstetrics and Gynecology, Faculty of Medicine Sriwijaya University/ Mohammad Hoesin Hospital, Palembang, Indonesia

\section{*Corresponding author:}

Hadrians Kesuma Putra

Department of Obstetrics and

Gynecology, Uroginecology

Division, Faculty of

Medicine Sriwijaya

University/ Mohammad

Hoesin Hospital, Palembang,

Indonesia

Email:

Hadrian@gmail.com

https://doi.org/10.37275/jacr.v1i2.148

\begin{abstract}
Introduction. MRKH syndrome is characterized by incomplete or absent of vaginal and uterine agenesis. Currently there are no official guidelines on the management of MRKH syndrome. This case report is about the operative management in MRKH patients by neovaginal with laparoscopic Davydov procedure.

Case presentation. A 26-year-old woman admitted that she had never had a period, the patient admitted that her breasts began to grow at the age of 13, and the patient was planning to get married, and refused to take further planning. The patient then came back to the RSMH urogynecology clinic after marriage, from theexamination it was found that the pubic hole was $\pm 0.5 \mathrm{~cm}$ deep, speculum examination could not be done, the uterus could not be palpable from the rectal toucher. From the ultrasound examination, it was found that both ovaries were within normal limits and suspected uterine hypoplasia. Hormone tests were within normal limits, with the following values: $\mathrm{LH} 27.01 \mathrm{mIU} / \mathrm{mL}$, FSH $57.08 \mathrm{mIU} / \mathrm{mL}$, Estradiol $10 \mathrm{pg} / \mathrm{mL}$, Prolactin $5.94 \mathrm{ng} / \mathrm{mL}$. Patients with a history of atrial septal defect (ASD) and ventricular septal defect (VSD)

Conclusion. Treatment of MRKH syndrome patients is usually complex and requires multidisciplinary counseling, therapy, and management, so it is hoped thatit can help patients to make a functional vagina. Further research and collaborationfrom various multidisciplinary make pregnancy in patients with MRKH syndrome,not impossible, along with current technological and scientific developments, the selection of surrogate mothers, and uterine transplantation is an option.
\end{abstract}

Key words: Mayer-Rokitansky-Kuster-Hauser Syndrome, Laparoscopy Neovaginal, Davydov Procedure, Epidural Anesthesia 


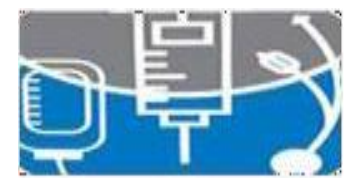

\section{Journal of Anesthesiology \& \\ ClinicalResearch}

\section{Introduction}

MRKH syndrome, first described by Mayer in 1829, followed by Rokitansky in 1838, Kuster in 1910 and Hauser et al, in 1961. This syndrome is characterized by incomplete or absent of vaginal and uterine agenesis. This syndrome occurs in 1 in 4.500 newborn girls. Patients with MRKH syndrome have normal secondary sex characteristics with a karyotype $46, \mathrm{XX}$. The patient main complaint for treatmentis usually amenorrhea or problems in sexual relations. This syndrome is classified into type I and type II. Type I includes uterovaginal aplasia, type II uterine aplasia, accompanied by other organ abnormalities, such as kidney, bone malformations, hearing loss and heart defects. MRKH syndrome is also known as Mullerian agenesis or Mullerian aplasia.

Although patients with MRKH syndrome are not likely to get pregnant, because the uterus is not formed or not functional, the ovaries are functional, and it is still possible to get pregnant with the help of a surrogate mother or uterus transplant. The differential diagnosis for vaginal agenesis is androgen insensitivity, low-lying vaginal septum, uterine and vaginal agenesis and imperforate hymen. In this case the ovaries may look normal. MRKH is associated with genetic disorders, but this has yet to be proven. Currently there are no official guidelines on the management of MRKH syndrome.

One of the operative managements in MRKH patients will be reported in this case, neovaginal with laparoscopic Davydov's procedure.

\section{Case Report}

A woman 26-year-old admitted that she had never had a period, the patient admitted that her breasts began to grow at the age of 13 , and the patient was planning to get married, and refused to take further planning. The patient then came back to the RSMH urogynecology clinic after marriage, from the examination it was found that the pubic hole was $\pm 0.5 \mathrm{~cm}$ deep, speculum examination could not be done, the uterus could not be palpable from the rectal toucher. From the ultrasound examination, it was found that both ovaries were within normal limits and suspected uterine hypoplasia. Hormone tests were within normal limits, with the following values: LH $27.01 \mathrm{mIU} / \mathrm{mL}$, FSH $57.08 \mathrm{mIU} / \mathrm{mL}$, Estradiol 10 pg / mL, Prolactin $5.94 \mathrm{ng} / \mathrm{mL}$. Patients with a history of atrial septal defect (ASD) and ventricular septal defect (VSD) and undergoing VSD and ASD repair surgery in 2012, the patient also suffered from 


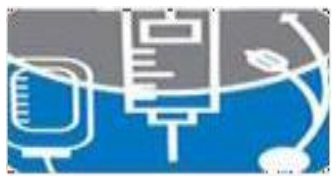

\section{Journal of Anesthesiology \& \\ Clinical Research}

scoliosis but was not treated.

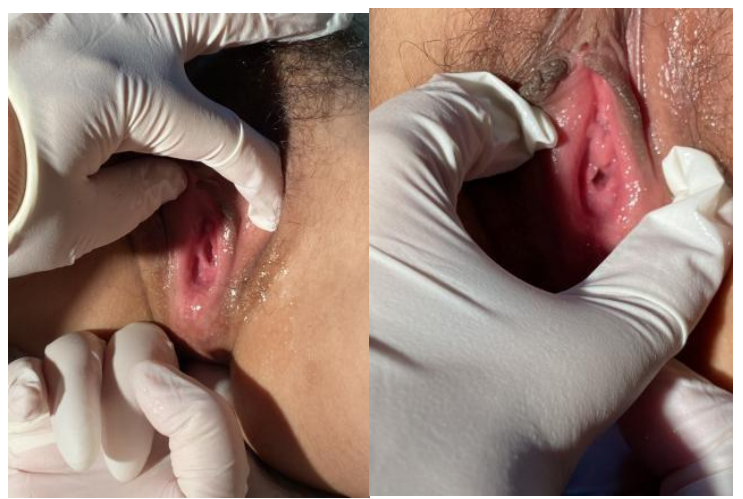

Figure 1. Vaginal agenesis before surgery

The patient was decided to undergo laparoscopic neovaginal surgery using the Davydov procedure. The first time a catheter was inserted and a neovagina was made by means of an incision in the vaginal mucosa, then the incision was deepened bluntly so that it reached the desired vaginal length. Then proceed with laparoscopy, by identifying the round ligament, opening the anterior peritoneum. In the caudal ligament of the round, the peritoneum is set aside as lateral as possible until it reaches the vesicouterine fold. Then do the opening of the posterior fold to the rectovaginal. Left and right peritoneal sutures were performed. The cork mold was installed which was covered with sterile condoms.

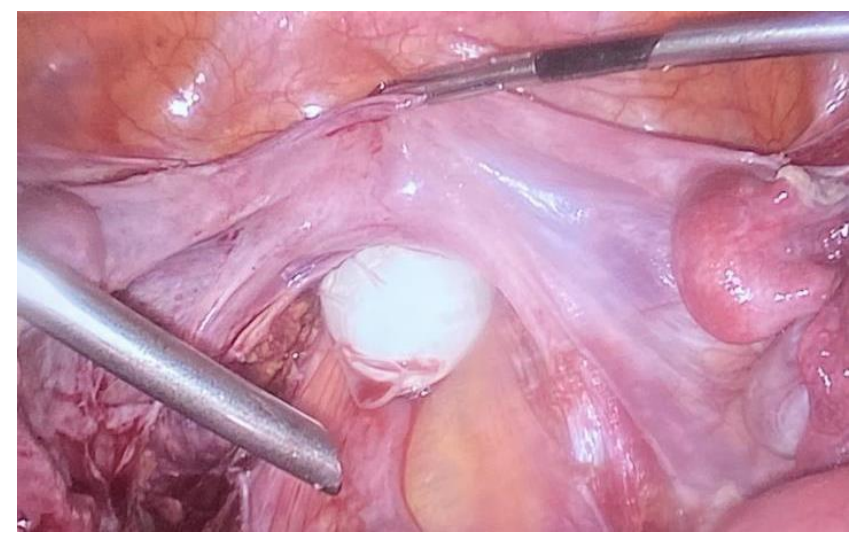

Figure 2. Vaginal cuff process 


\section{Journal of Anesthesiology \& \\ Clinical Research}

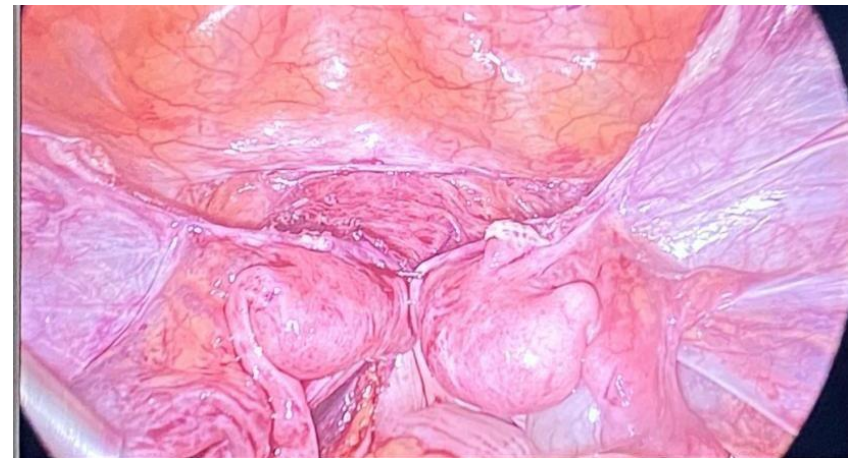

Figure 3. Post operative

\section{Post operative care}

The mold was removed after 10 days postoperatively and was taught to install the mold itself, the patient was advised to wear the mold 6-8 hours per day for 3 months, when the patient went home.

\section{Discussion}

The first-line therapy of vaginal agenesis is non-surgical dilation, known as the Frank and Ingram procedure. But this method is not widely chosen because some women are not comfortable with the use of dilators, so the surgical technique is preferred by patients with cases of vaginal agenesis. Although the use of dilators is still done after surgery to maintain the shape of the vagina. Previously the choice of vaginal reconstruction surgery was the use of intestinal segments, especially the use of the sigmoid colon which was first introduced by Wallace, in 1911. This technique is claimed to be better than skintransplantation techniques, but requires a long time for surgery and the possibility of necrosis in the vagina. ileum and intraluminal abscess. The laparoscopic Davydov technique has several advantages, namely a relatively shorter operating time, fewer intraoperative complications, and no large external scar. ${ }^{4,5}$

The choice of anesthetic technique for this patient was regional; epidural anesthesia, considering the condition of the patient with a history of closure surgery for ASD and VSD defects, the estimated length of the surgical procedure, as well as consideration of good muscle relaxation during surgery, adequate pain control both during surgery and postoperatively, and finally a fast postoperative recovery. So, in this patient regional epidural anesthesia was performed with a target height of the 6 thoracic vertebrae sensoryblock with 2-3 lumbar vertebrae insertion sites with local anesthetic drugs, $0.5 \%$ bupivacaine isobaric, 


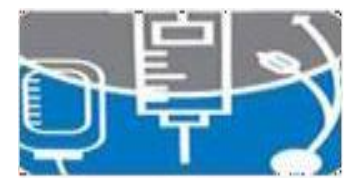

\section{Journal of Anesthesiology \& \\ Clinical Research}

loading dose of $12 \mathrm{ml}(60 \mathrm{mg})$. The sensory block height was achieved segmentally between thoracal 6 to lumbar 3 and motor block was achieved with a Bromage score of 3. Intraoperative sedation using a target was controlled infusion (TCI) of propofol $1.2 \mathrm{ug} / \mathrm{ml}$, target moderate-deep sedation with a sedation score of 5-6. The top up dose of epidural anesthesia was carried out 90 minutes after the first dose, which was 6 $\mathrm{ml}$ of $0.5 \%$ bupivacaine isobaric local anesthetic.

The operation lasts 2.5 hours. Stable intraoperative hemodynamics, systolic blood pressure 120-130 $\mathrm{mmHg}$ and diastolic blood pressure 70-80 $\mathrm{mmHg}$, pulse rate 70-80 beats per minute. The patient is optimally sedated (moderate-deep sedation) even with operator manipulation. Minimal intraoperative bleeding, sufficient urine production. There are no complications both during and after surgery, such as hypotension, nausea, vomiting, shoulder pain, PDPH, and paresthesia.

When the operation is over, the propofol TCI is switched off, the patient regains consciousness and is observed in the recovery room. Hemodynamically stable, NRS score 0. Postoperative analgesic using continuous $0.125 \%$ bupivacaine isobaric, $5 \mathrm{cc}$ per hour via an epidural catheter and paracetamol $500 \mathrm{mg}$ orally every 8 hours. The patient was returned to the treatment room with an NRS score of 0 and Bromage Score 2.

\section{Conclusion}

Treatment of MRKH syndrome patients is usually complex and requires multidisciplinary counseling, therapy, and management, so it is hoped that it can help patients to make a functional vagina. Further research and collaboration from various multidisciplinary make pregnancy in patients with $\mathrm{MRKH}$ syndrome, not impossible, along with current technological and scientific developments, the selection of surrogate mothers, and uterine transplantation is an option.

\section{Reference}

1. Takahashi K, Nakamura E, Suzuki S, Shinoda M, Nishijima Y, Ohnuki Y, et al. Laparoscopic Davydov Procedure for Mayer-Rokitansky-Kuster-Hauser Syndrome: Analysis for 7 cases. Tokai J Exp Clin Med. 2016. 81-87

2. Omotayo OL, Ogunkeyede AO, Adewale MA, Olatinwu AO. Case-report: Successful Laparoscopic 


\section{Sournal of Anesthesiology 8 \\ Clinical Research}

Assisted Davydov Operation for the Treatment of Complete Congenital Vaginal Agenesis at a Public Health Facility in Ilorin, Nigeria. Saudi J Health Sci. 2016. 93-96

3. Herlin MK, Petersen MB, Brannstrom M. Mayer-Rokitansky-Kuster-Hauser (MRKH) syndrome: a Comprehensive Update. Orphanet J Rare Dis. 2020; 15: 214.

4. Klosowicz E, Komenda J, Zmaczynski A, Doroszewska K, Janssen OK, Plonka M, et all. Patient with Mayer-Rokitansky-Kuster-Houser Sunsrome (MRKH) Who Underwent Laparascopic DavydovMoore Vaginoplasty. I Med Pub J, 2020; 1-2

5. Sonny S. Neovagina with intestines. HUGI PIT. 2012.

6. Butterworth JF, Mackey DC, Wasnick JD. Spinal, Epidural, \& Caudal Blocks. In: Morgan \& Mikhail's Clinical Anesthesiology. 6th ed. 2018. 